\title{
Cultivation of Schizophyllum commune mushroom on different wood substrates
}

\author{
P.N. Dasanayaka* and S.C. Wijeyaratne \\ Department of Botany, University of Sri Jayewardenepura, Sri Lanka
}

Date Received: 01-05-2017

Date Accepted: 05-06-2017

\begin{abstract}
Schizophyllum commune is an edible mushroom grown on wood under natural conditions. Present study focused on cultivation of S.commune on different wood substrates since it is not commercially cultivated. A pure culture of $S$. commune was obtained by growing a tissue of the mushroom on Potato Dextrose Agar (PDA) medium. Spawns were produced by growing the mycelium on paddy grains. Mushroom was cultivated on sawdust of seven different wood substrates. The maximum yield was observed in sawdust of jackfruit (Artocarpus heterophyllus) followed by sawdust of rambutan (Nephelium lappaceum) and country almond (Terminalia catappa). A significant difference was not observed when mango (Mangifera indica) elephant apple (Dillenia indica), tulip wood tree (Harpullia arborea) and thungfaa (Alstonia macrophylla) sawdust used as substrate. The lowest yield was observed in thungfaa (Alstonia macrophylla) sawdust. Effect of some additives on the yield was studied and significant difference in yield was observed when rice bran and used-tea leaves used as additives. Effect of rice bran on yield was studied using different ratios of sawdust to rice bran and the highest was observed in 2:1 ratio of sawdust to rice bran. The best incubating temperature for mycelial growth on the substrate was $35^{\circ} \mathrm{C}$. The composition of the mushroom on a dry weight basis was; $71.4 \%$ moisture, $23.35 \%$ crude protein and $6 \%$ ash. Tested wood species are promising substrates for cultivation of S.commune as cottage industry.
\end{abstract}

Key words: Schizophyllum commune, mushroom, cultivation, sawdust, spawn

\section{Introduction}

Mushrooms are fleshy, spore-bearing fruiting bodies of basidiomycete fungi, typically produced above ground on soil or on its food source. Edible mushrooms are recommended by the FAO as food, to meet protein requirement of developing countries, the large proportion of which depends mainly on cereals. In general edible mushrooms are low in fat and calories, rich in vitamins B, D, K and sometimes vitamins A and C (Alam et al., 2007), contain more protein than any other food of plant origin and are also a good source of mineral nutrients (Qin, 1989). Therefore great attention has been paid on mushroom as 'functional food' to complement and supplement a healthy diet as well as for their significant role in human disease control (Chang 1999, Khan et al., 2009). S.commune is also an edible fungus and growing under natural conditions especially during rainy season on decaying woods. It has been isolated all continents except Antarctica (Khatua et al., 2013). S.commune is known to be a very good source of proteins, vitamins, lipids and mineral elements (Adejoye et al., 2007). It is rich in $\mathrm{P}, \mathrm{Mg}, \mathrm{K}$, and Se and high dietary fiber content more than $50 \%$ of the net weight (Ghorai et al., 2009). Although S.commune grows on decaying woods of different species under natural conditions there are no records on its commercial cultivation. Therefore present study was undertaken to evaluate the possibility of cultivating S.commune on freely available wood substrates and their effect on yield of the mushroom, and the effect of temperature on the growth of S.commune mycelium on the substrate in compost bags.

*Correspondence: nilanthiedas@sjp.ac.lk

Tel: +94718122358

ISSN 2235-9370 Print / ISSN 2235-9362 Online @2017 University of Sri Jayewardenepura 


\section{Materials and Methods}

This study was conducted at the Department of Botany, University of Sri Jayewardenepura, Nugegoda, Sri Lanka. Fruiting bodies of Schizophyllum commune growing on decaying mango wood were collected from Eheliyagoda area of Rathnapura district, Sri Lanka.

\section{Production of spawn}

Pure culture of the S.commune mycelium was obtained by growing a tissue of fruiting body aseptically on PDA medium. Boiled paddy grains were used as the substrate to produce the spawn. Boiled paddy grains were sterilized at $121^{0} \mathrm{C}$ under $15 \mathrm{lb} / \mathrm{inch}^{2}$ in conical flasks. After the sterilization the substrate was inoculated with $1 \mathrm{~cm}^{2}$ mycelial blocks of S.commune grown on PDA at room temperature and inoculated the substrate was incubated at room temperature.

Effect of kinds of sawdust on the yield of the mushroom

\section{Collection of sawdust}

Sawdust of seven different woods; Alstonia macrophylla, Artocarpus heterophyllus, Harpullia arborea, Mangifera indica, Dillenia indica, Nephelium lappaceum and Terminalia catappa were collected from two different saw mills of Eheliyagoda (Table 01) and was sun dried for about 4-5 days depending on its moisture content.

Table 01: Different kinds of sawdust used in the study.

\begin{tabular}{llll}
\hline English Name & Local Name & Scientific Name & Family \\
\hline Thungfaa & Hawari Nuga & Alstonia macrophylla & Apocynaceae \\
Jackfruit & Kos & Artocarpus heterophyllus & Moraceae \\
Tulip wood tree & Na Imbul & Harpullia arborea & Sapindaceae \\
Mango & Amba & Mangifera indica & Dilleniaceae \\
Elephant apple & Honda para & Dillenia indica & Sapindaceae \\
Rambutan & Rambutan & Nephelium lappaceum & Combretaceae \\
Country almond & Kottamba & Terminalia catappa & Anacardiaceae \\
\hline
\end{tabular}

Preparation of different wood substrates

Composition of the substrate

$\begin{array}{ll}\text { Sawdust } & 400 \mathrm{~g} \\ \text { Rice bran } & 40 \mathrm{~g} \\ \mathrm{CaCO}_{3} & 10 \mathrm{~g} \\ \mathrm{MgSO}_{4} & 1 \mathrm{~g} \\ \text { Water } & 600 \mathrm{~mL}\end{array}$

Polypropylene bags $(10.5 \mathrm{~cm} \mathrm{X} 15 \mathrm{~cm})$ were filled with $400 \mathrm{~g}$ of thoroughly mixed substrates and mouths were plugged by inserting water absorbing cotton wool with the help of plastic rings. Each of seven treatments was replicated five times.

T1: Sawdust of Alstonia macrophylla (Thungfaa)

T2: Sawdust of Artocarpus heterophyllus (Jackfruit)

T3: Sawdust of Harpullia arborea (Tulip wood tree)

T4: Sawdust of Mangifera indica (Mango)

T5: Sawdust of Dillenia indica (Elephant apple)

T6: Sawdust of Nephelium lappaceum (Rambutan)

T7: Sawdust of Terminalia catappa (Country almond)

The bags were autoclaved at $121^{0} \mathrm{C}$ under $15 \mathrm{lb} / \mathrm{inch}^{2}$ pressure and allowed to cool overnight. Thereafter each bag was inoculated with two tea spoons of prepared spawn of S.commune mushroom. The inoculated bags of seven treatments with five replicates were arranged following randomized 
block design (RBD) and incubated at room temperature under dark conditions till the mycelium grew throughout the substrates. Then the bags were opened and watered three times a day. First flush of fruiting bodies was harvested 30 days after inoculation. The fresh weight of mushroom harvested from each bag was recorded.

\section{Effect of some additives on yield of the mushroom}

Effect of four different additives: coir dust, rice bran, dried Ipillpil leaves and used tea leaves, on the yield of $S$. commune mushroom was determined by adding $10 \%$ of additive to the basal medium.

\section{Effect of rice bran on yield}

Effect of rice bran (the best out of tested additives) on the yield of S.commune mushroom was studied using six different ratios of sawdust to rice bran. Substrates were prepared mixing sawdust and rice bran in different ratios. Sawdust of Artocarpus heterophyllus was used for this experiment.

T1 - Sawdust to rice bran ratio 6:1

T2 - Sawdust to rice bran ratio 5:1

T3 - Sawdust to rice bran ratio $4: 1$

T4 - Sawdust to rice bran ratio 2:1

T5 - Sawdust to rice bran ratio 1:1

T6 - Sawdust to rice bran ratio 1:0 (control experiment)

The cultivation bags of six treatments were prepared with five replicates. Sterilized substrate filled bags were inoculated with spawns of S.commune mushroom. The inoculated bags of six treatments with five replicates were arranged following randomized block design (RBD) and incubated at room temperature till the mycelium grew throughout the substrate. They were opened and watered three times a day. First flush of fruiting bodies were harvested 30 days after the inoculation. The fresh weight of mushroom harvested from each bag was recorded.

\section{Effect of temperature on mycelial growth in compost bag}

Effect of temperature on the growth of mycelium on the substrate in compost bags were studied using six different temperatures: $15^{0} \mathrm{C}, 20^{\circ} \mathrm{C}, 25^{\circ} \mathrm{C}, 30^{\circ} \mathrm{C}, 35^{\circ} \mathrm{C}$ and $40^{\circ} \mathrm{C}$. The substrate was prepared using Artocarpus heterophyllus sawdust, rice bran, $\mathrm{CaCO}_{3}$ and $\mathrm{MgSO}_{4}$ with five replicates for each temperature. The distance of the mycelial growth from the place of inoculation was measured daily until it covered the substrate in the bag completely.

\section{Determination of moisture, ash and total nitrogen content of S.commune mushroom}

Two grams of the mushroom was dried in an oven at $105^{\circ} \mathrm{C}$ until the sample gave a constant weight to determine the moisture content. Two grams of dried mushroom weighed accurately into a porcelain crucible was ignited in a muffle furnace at $550^{\circ} \mathrm{C}$ until gray ash resulted. It was left to cool and weight of the sample was recorded.

Total nitrogen content of the mushroom was determined by the standard Micro-Kjeldal procedure. Following this method protein content of the sample was calculated by multiplying total nitrogen content by 6.25 . 


\section{Results}

Growth of white mycelium around the tissue was observed three days after inoculation on PDA medium. Growing of septate mycelium with clamp connections was observed under the microscope confirming its growth.

The yield of S. commune mushroom grown on sawdust of seven different wood species is shown in Figure 1. Significant variation was found in the yield of the mushroom grown on these seven different substrates. The maximum yield was observed with sawdust of Artocarpus heterophyllus (T2) followed by sawdust of Terminalia catappa (T7) Nephelium lappaceum (T6) and relatively lower yields were recorded when Mangifera indica (T4) Dillenia indica (T5), Harpullia arborea (T3) and Alstonia macrophylla (T1) sawdust used as substrates. The lowest yield was observed in Alstonia macrophylla sawdust.

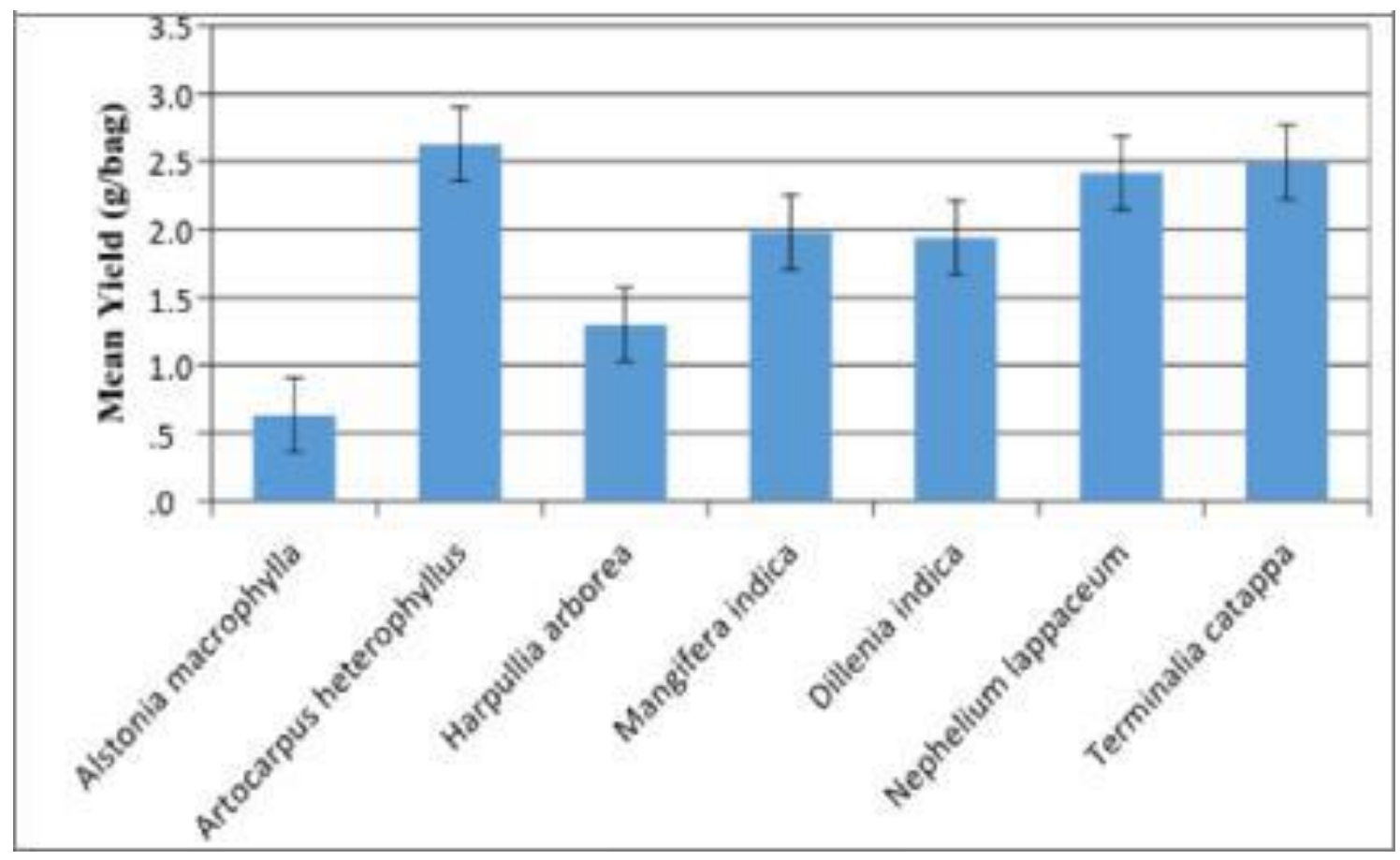

Figure 1: Yield of S. commune growing on different wood substrates

Rice bran treatment and used-tea leaves treatment showed significant difference in yield when compared to the control. There was no significant difference in yield when Ipillpil leaves and coir dust were used as substrate (Figure 2). 


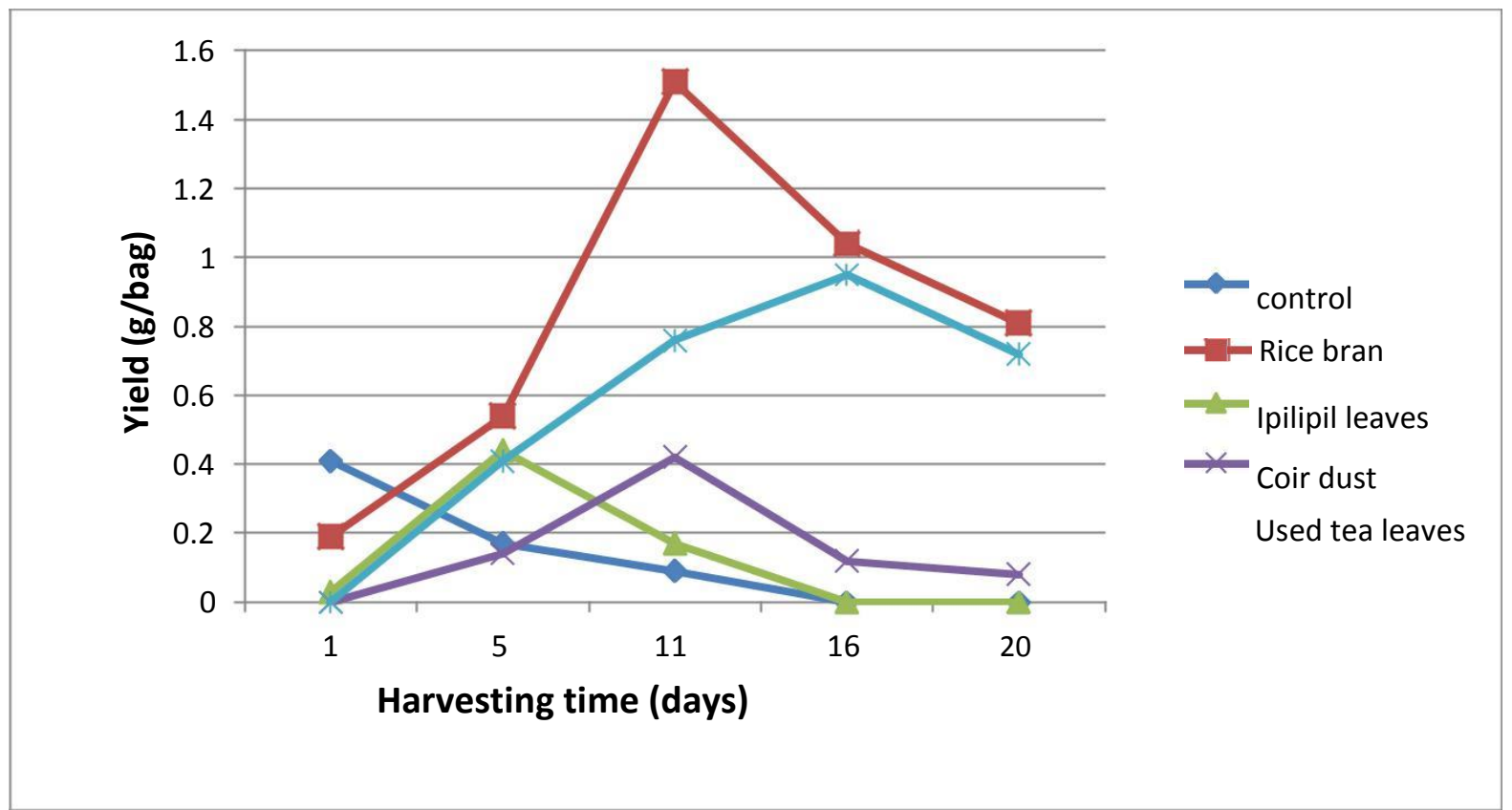

Figure 2: Yield of S. commune with four different additives

The mushroom was cultivated using six different ratios of sawdust to rice bran to find out the most suitable ratio for its growth. The best yield was obtained when the sawdust to rice bran ratio was 2:1. The yield decreased when the ratio was increased or decreased from 2:1 ratio (Figure 3).

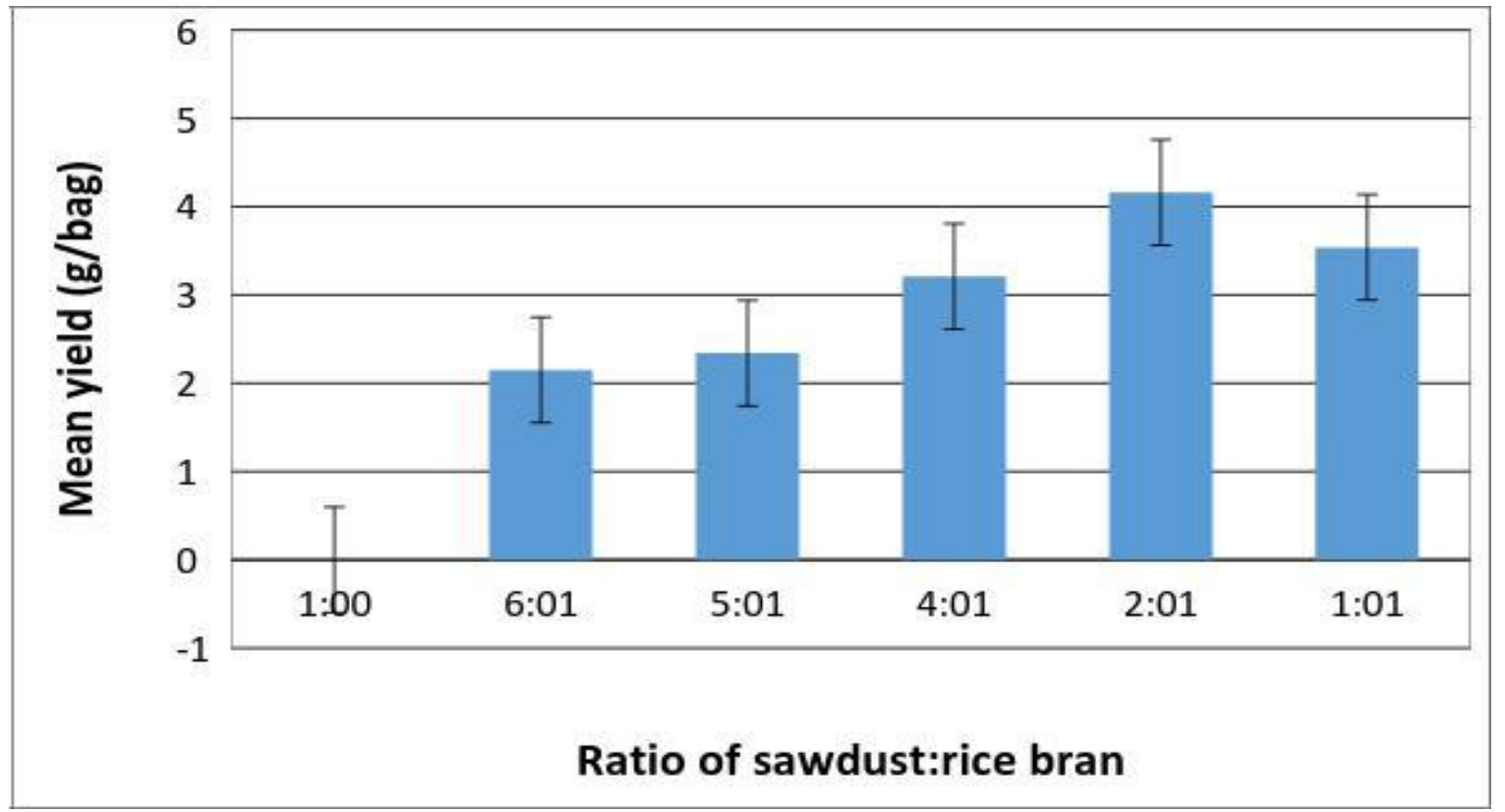

Figure 3: Mean yield of S.commune mushroom on substrates with different ratios of sawdust to rice bran.

Mean number of mushroom harvested from bag was also recorded and relatively higher number of mushrooms were harvested from bags which filled with sawdust to rice bran with 4:1, 2:1, and 1:1 ratios (Figure 4). 


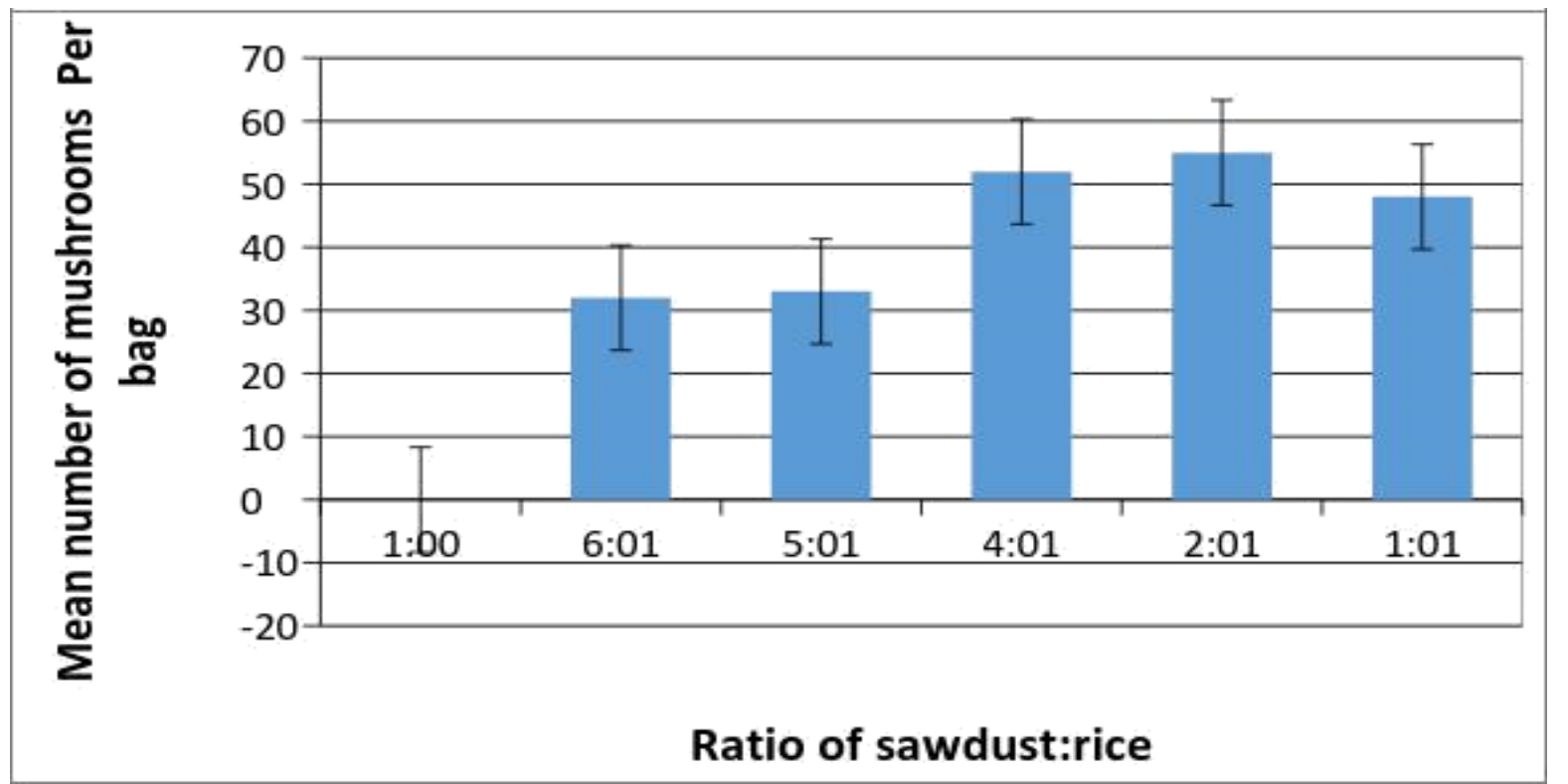

Figure 4: Mean number of S.commune mushrooms per bag on substrates with different ratios of sawdust to rice bran.

Results revealed that the best temperature for mycelial growth was $35^{0} \mathrm{C}$ and spawn running took 11 days after inoculation to cover the whole culture bag at $35^{\circ} \mathrm{C}$ while spawn running time was longer at all other tested temperatures (at $30^{\circ} \mathrm{C}, 25^{\circ} \mathrm{C}$ and $20^{\circ} \mathrm{C}$ it took 13,21 and 24 days respectively) (Figure 5). No growth of mycelium was observed at $15^{\circ} \mathrm{C}$ and $45^{\circ} \mathrm{C}$.

The composition of the mushroom on a dry weight basis was; $71.4 \%$ moisture, $23.35 \%$ crude protein and $6 \%$ ash.

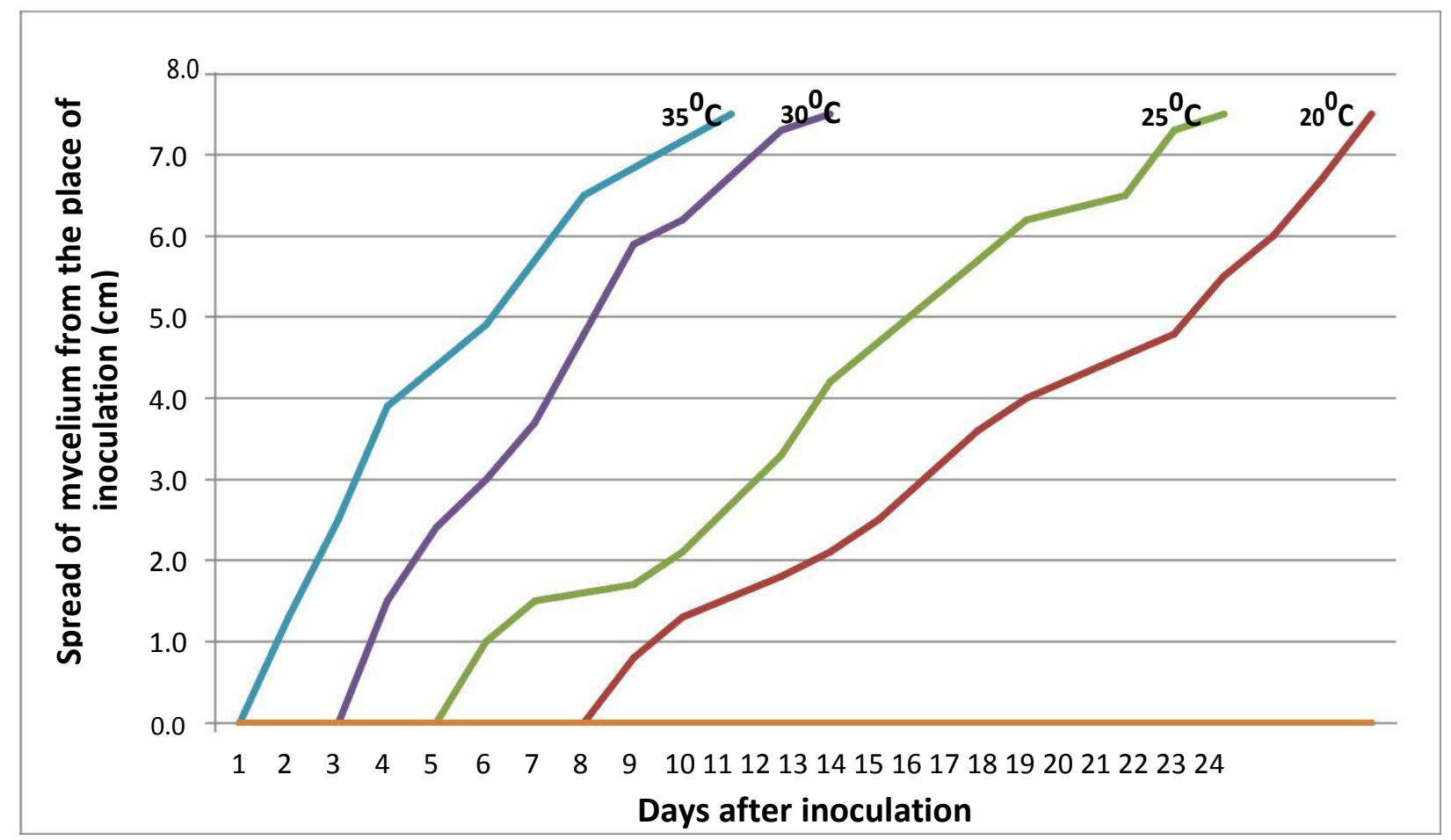

Figure 5: Effect of temperature on mycelial growth of S.commune

\section{Discussion}

Mushrooms depend on the substrate for nutrition and the substrate is normally a source of lignocellulose material which support growth, development and fruiting of mushrooms (Chang and Miles, 2004). Decaying wood is a well-known substrate for the growth of $S$. commune mushroom. Therefore the mushroom was cultivated on seven different wood substrates for the recommendation of 
more suitable substrate for the commercial cultivation of this mushroom. Significant variation was found in the yield of $S$. commune mushroom grown on sawdust of seven different wood species. The maximum yield was observed with sawdust of Artocarpus heterophyllus followed by sawdust of Nephelium lappaceum and Terminalia catappa. A significant difference was not observed when Mangifera indica, Dillenia indica, Harpullia arborea and Alstonia macrophylla sawdust used as substrates. The lowest yield was observed in Alstonia macrophylla sawdust. The results of the present study are supported by findings of the study conducted by Ashrafuzzaman et al., 2009. They have studied effect of sawdust of Acacia nilotica (Babul tree), Michelia champaca (Teak shambul), Dipterocarpus alartus (Garjan), Leucaena glauca (IpilIpil), Artocarpus heterophyllus (Jackfruit), Mangifera indica (Mango), Albizia saman (Raintree), Tectona grandis (Teak), Bombax ceiba (Silk cotton), Dalbergia sissoo (Blackwood - tree) on the growth and yield of shitake mushroom (Lentinus edodes). Significantly faster mycelial growth has been observed on jackfruit substrate compared to other substrates. Higher number of primodia and effective fruiting bodies have been recorded on jackfruit sawdust. It has been found that mycelial running rate was secondly higher on mango sawdust and have not shown any significant difference when babul tree, teak and silk cotton sawdust used as substrate. Ediriveera et al.,(2015) have also investigated the effect of banana leaves, coconut leaves, paddy straw and coir dust on the growth and yield of $S$. commune. Higher rate of mycelial growth has been observed in mixture containing banana leaves and not even a sign of mycelial growth has been observed in the medium containing paddy straws. Significantly higher yields have been recorded for coconut leaves and coir dust containing mixtures.

Regardless of the main ingredient used, starch - based supplements such as rice bran, wheat bran, millet, rye or corn can be added at 10 to $40 \%$ of dry weight to the main ingredient (Royse et al., 1990; Royse 1996; Ivan et al., 2003). Nawanze et al., 2005 reported some of the proven additives induce fruiting body formation. Rice bran, cassava peels, carbohydrates such as glycogen, natural extracts like yeast and vegetable oils and fish oil found as effective additives.

The yield of S.commune was evaluated with four different additives to find out the best additive towards the increased production. Rice bran treatment and used-tea leaves treatment showed significant difference in yield when compared to the control. There was no significant difference in yield when Ipillpil leaves and coir dust were used as additives.

The best yield was obtained when the sawdust to rice bran ratio was $2: 1$. When water is added to the medium $(1: 1)$, rice bran get adhered and cause the reduction in bulkiness and this is not the case when there is more sawdust in the substrate. The control contained only sawdust, $\mathrm{CaCO}_{3}$ and $\mathrm{MgSO}_{4}$ and the mycelium did not grow well on it. After opening the control bag a very small number of buttons appeared and these even did not open up indicating the poor nutritional status of the substrate. Since rice bran is proven to be as an effective additive and it is readily available in Sri Lanka which can be used as potential additive.

An experiment was carried out to see the effect of rice bran on yield of mushroom using six different ratios of sawdust to rice bran. Mean number of mushroom harvested from bag was also recorded and relatively higher numbers of mushrooms were harvested from bags which filled with sawdust to rice bran with $4: 1,2: 1$, and 1:1 ratios.

Temperature is a very important environmental factor for mycelium growth of fungi. Results revealed that the best temperature for $S$. commune mycelial growth was $35^{\circ} \mathrm{C}$. The mycelial growth appeared to be suppressed at the temperatures higher or lower than $35^{\circ} \mathrm{C}$. Jonathan (2002) also reported that the growth of $S$. commune as inhibited at $45^{\circ} \mathrm{C}$ and $50^{\circ} \mathrm{C}$.

The composition of the mushroom on a dry weight basis was; $71.4 \%$ moisture, $23.35 \%$ crude protein and $6 \%$ ash. Incorporation of rice bran into the wood substrates enhanced mushroom 
production. Tested wood species are promising substrates for cultivation of S.commune as cottage industry.

\section{Conclusions}

Artocarpus heterophyllus sawdust appeared as the most suitable substrate out of the tested substrates for cultivation of S.commune in compost bags. Rice bran promoted the mushroom production and sawdust to rice bran ratio 2:1 gave the highest yield. Optimum temperature for the mycelial growth and mushroom production was $35^{0}$ C. S.commune mushroom can be harvested 30 days after inoculation of the spawn into compost bags. Wood substrates of Terminalia catappa and Nephelium lappaceum were also promising substrates for commercial production of S.commune mushroom. Relatively higher protein content of the mushroom and availability of wood substrates in Sri Lanka make commercial cultivation of S.commune as economically feasible cottage industry.

\section{References}

Adejoye, O.D., Adebayo-Tayo, B.C., Ogumjobi, A.A., Afolabi, O.O. 2007. Phytochemical studies on Schizophyllum commune (Fries) a Nigerian fungus. World ApplSci J. 2(1),73-76.

Alam, N., Khan, A., Hossian M.S., Amin, S.M.R., Khan, L.A.2007 Nutritional analysis of dietary mushroom Pleurotus florida Egger and Pleurotus sajorcaju (Fr) Singer. Bangladesh J Mushroom 1(2):1-7).

Ashrafuzzaman, M., Kumruzzaman, A.K.M., Ismail, M.R., Shahidullah Fakir, S.A. 2009. Substrate affects growth and yield of shitake mushroom. African Journal of Biotechnology. 8(13),29993006.

Chang, S. 1999. World production of cultivated edible and medicinal mushroom in 1997 with emphasis on Lentinus edodes (Berk) Singer In China Int I Med Mushrooms. 1,291-300.

Chang, S.T. and Miles, P.G. 2004. Mushroom cultivation, nutritional value, medicinal effect, and environmental impact, $2^{\text {nd }}$ ed. CRC Press, Boca Raton, FL.

Chang, S.T. and Quimio, T.H. 1976. Tropical Mushroom Biological Nature and cultivation methods.

Ediriveera, S.S., Wihjesundara, R.L.C., Nanayakkara C.M., Weerasena O.V.D.S.J 2015. Comparative study of growth and yield of edible mushrooms, Schizophyllum commune Fr., Auricularia polytricha (Mont.) Sacc.And Lentinus squarrosulus Mont. On lignocellulosic substrates. Micosphere 6(6):760-765.

Ghorai, S., Banik, S.P., Verna, D., Chowdhury, S., Mukherjee, S., Khowala, S. 2009. Fungal biotechnology in food and feed processing. Food Res Int. 42,577-587.

Ivan, H.R., Antonio, C.M., Jose, O.M., Jose, C.B. 2003. Supplementation of sugarcane bagasse with rice bran and sugarcane molasses for shitake (Lentinula edudes) spawn production. Brazil J. Microbiol. 34, 61-65.

Jonathan S.G., 2002. Vegetative growth requirements and antimicrobial activities of some higher fungi in Nigeria. PhD thesis, University of Ibadan, Ibadan, Nigeria.

Khan, M.A., Khan, L.A., Hossain, M.S., Tania, M., Uddin, M.N. 2009. Investigation on nutritional composition of common edible and medicinal mushrooms cultivated in Bangladesh. Bangladesh J Mushroom. 3(1),21-28.

Khatua, S., Paul, S., Acharya, K. 2013. Mushroom as the potential source of new generation of antioxidant: A review. Research J. Phar and Tech 6(5), 496-505.

Nawanze, P.L., Khan, A.U., Amesh, J.B., Umoh, V.J. 2005. The effect of the interaction of various spawn grains with different culture medium on carophore dry weights and stipe and pileus diameter of Lentinus squarrosuhus (Mont) Singer Afr J Biotechnol. 4(7),615-619. 
Qin, S.X., 1989. Effect of different cultivation materials on nutritive composition of Pleurotus fruiting bodies. Edible fungi of China, 3:12-13.

Royse, D.J. 1996. Yield simulation of shitake by millet supplementation of wood chip substrate. Mushroom Biol. Mushroom Prod. 2, 277-283.

Royse, D.J., Bahler, B.D., Bahler, C.C. 1990. Enhanced yield of shitake by saccharide amendment of the synthetic substrate. Appl Environ, Microbiol, 56, 479-482. 